\title{
Basal and post-ischemic vascular compliance in children/ adolescents born small for gestational age
}

\author{
Mirella Strambi • Gianluca Messa • Silvia Berni • \\ Serena Capitani • Andrea Pammolli • \\ Francesca Iacoponi • Costantina Censurato • \\ Caroline Magne Tene $\cdot$ Alessandro Fiorica • \\ Aurelio Vittoria
}

Received: 17 August 2011 /Revised: 22 March 2012 /Accepted: 23 March 2012 /Published online: 10 May 2012

(C) The Author(s) 2012. This article is published with open access at Springerlink.com

\begin{abstract}
Background Intrauterine growth restriction plays a powerful role in influencing later susceptibility to certain chronic diseases, such as hypertension. Endothelial dysfunction and arterial stiffness are early events in the development of cardiovascular diseases (CVDs). We have studied vascular compliance in small for gestational age (SGA) children/ adolescents in comparison with that in appropriate for gestational age (AGA) subjects.

Methods We monitored blood pressure, vascular resistance and compliance in 82 children-adolescents (52 SGA, 30 AGA), by means of pulse wave analysis (CR $2000 \mathrm{HDI}$ ) at the radial level, before and after 3 min of ischemic stress at the brachial level.

Results In the children/adolescents born SGA we found a significant increase in systolic and diastolic blood
\end{abstract}

\footnotetext{
M. Strambi $(\bowtie) \cdot$ S. Berni

Department of Paediatrics, Obstetrics and Reproductive Medicine,

University of Siena,

Viale Bracci 36,

53100 Siena, Italy

e-mail: strambi@unisi.it

G. Messa $\cdot$ C. Censurato $\cdot$ C. Magne Tene $\cdot$ A. Fiorica $\cdot$ A. Vittoria Department of Clinical Medicine and Immunological Science, University of Siena,

Siena, Italy

S. Capitani $\cdot$ A. Pammolli

Department of Physiopathology, Experimental Medicine

and Public Health, University of Siena,

Siena, Italy

F. Iacoponi

Department of Biomedical Sciences, Section of Applied Biology, University of Siena,

Siena, Italy
}

pressure and vascular resistance in the basal condition; the large and small vessels were stiffer. After ischemia we observed an increased vascular response in the SGA children/adolescents: there was a great diminution of systolic and diastolic blood pressure and a larger increase of the elasticity of the conduit and resistance vessels.

Conclusions These data show that the SGA group presented some early signs of arterial wall functional disorders. More pediatric data are needed for the evaluation by non-invasive techniques of vascular function in children-adolescents at risk of CVD.

Keywords Hypertension - Small for gestational age · Vascular disease $\cdot$ Arterial stiffness

\section{Introduction}

An extensive body of research has shown that birth weight is related to adverse outcomes, such as hypertension, risk of coronary heart disease and type 2 diabetes, with smaller babies having a greater risk with age [1-4], with findings of the early studies of Barker et al. [1,2] being confirmed in later studies [3, 4]. An inverse relationship between adult blood pressure and gestational age has been found in both adult men and women who were born prematurely $[5,6]$ and repeatedly confirmed $[7,8]$. In the context of a low birth weight (LBW) considered to be an expression of an increased risk of developing cardiovascular diseases (CVDs) later in life, recent studies have indicated that it may not be preterm birth per se that is a risk factor for CVDs but rather the relationship between intrauterine growth restriction (IUGR) and cardiovascular or metabolic disorders in adult life [9-12]. 
The underlying mechanisms are still not clear, but genetic factors associated with fetal growth restriction and increased risk of CVDs may be involved [13-15].

Reduced arterial elasticity, measured also in terms of vascular compliance, stiffness, or distensibility, is an early sign of vascular damage and can be used as a surrogate marker of arterial function [16, 17]. Assessment of arterial elastic properties helps to identify subclinical cardiovascular pathologies [18], enabling prevention and targeted early treatment [16], and it may also enable the effects of therapy to be evaluated [19,20].

Vascular endothelial dysfunction is a key event in the development of diseases associated with birth weight [21], and a positive association between LBW and endothelial dysfunction has been demonstrated in young adults $[22,23]$ and children [21,24]. The evaluation of brachial artery endothelial function (flow-mediated dilation, FMD) is now increasingly used for paediatric cardiovascular risk evaluation [25].

To explore vascular function in a very early phase of life (children or adolescents) we studied the vascular compliance of two groups of subjects divided according to birth weight. We checked arterial compliance before and after ischemic stimuli in a group of SMA children/adolescents monitoring conduit compliance and vessel resistance by radial pulse wave analysis. We also examined induced vascular reactivity after a standardized ischemic stimulus.

\section{Methods}

\section{Study population}

From April 2008 to April 2009, we studied 82 children and adolescents ( 48 boys, 34 girls, age range $8-16$ years). They were divided into two groups according to birth weight and gestational age [26, 27]. IUGR, antenatally diagnosed, was defined as insufficient fetal growth $<2$ standard deviation (SD) (or $<3$ rd percentile) below the average for gestational age, and SGA at birth was defined as insufficient body size of $<2$ SD (or $<3$ rd percentile) below the average for weight and/or length in relation to gestational age and gender for the Italian population.

We enrolled 52 Italian children/adolescents with a gestational age of 37-38 weeks into the SGA/IUGR group (32 males, 20 females); these children had been followed up in a regular clinical program. The average birth weight was $1,684 \pm 520 \mathrm{~g}$, the average head circumference at birth was $31.8 \pm 1.8 \mathrm{~cm}$, and the average age at the time of examination was $12.40 \pm$ 2.47 years. The control group comprised 30 children/ adolescents (16 males, 14 females) born full term and with the appropriate weight for gestational age (AGA); the average age at the time of examination was $12.27 \pm 1.74$ years. The subjects of both groups were nonobese, and they were all at Tanner developmental stage 2 .
Blood pressure measurements were obtained from the right arm of each subject in a supine position. The proper cuff size was ensured by arm measurements. Systolic and diastolic blood pressures (SBP, DBP, respectively) were determined by automated oscillometric monitors (HDI/Pulse Wave CR-2000; Hypertension Diagnostics, Eagan, MN). The clinical characteristics of the 52 SGA children/adolescents and the 30 age- and sex-matched AGA children/adolescents of the control group are summarized in Table 1.

Exclusion criteria were known congenital or acquired cardiovascular, hepatic, renal, or brain diseases, genetic syndromes, and chronic gastrointestinal diseases, such as celiac, metabolic, or endocrine disorders.

The Institutional Local Ethical Committee of the Siena University Hospital (AOUS S. Maria alle Scotte) approved the study. Informed consent was obtained from older children and from both parents of all children after a full explanation of the study prior to enrolment.

\section{Study protocol}

The subjects were studied between 1500 hours and 1800 hours; after $15 \mathrm{~min}$ of rest in a quiet, temperaturecontrolled room, with the subject in a recumbent position, BP measurement and pulse wave analysis (PWA) were performed three times at 5-min intervals. We then provoked an ischemic stimulus with a cuff placed on the brachial segment of the forearm inflated to a pressure exceeding the systolic arterial blood pressure so that the radial homolateral oscillometric curve disappeared for exactly $3 \mathrm{~min}$. The BP measurement and PWA were repeated four times at 5-min intervals.

Assessment of arterial elasticity

Diastolic pulse contour analysis uses a modified Windkessel model to derive information on proximal and distal arteries by analyzing the diastolic portion of the pressure pulse

Table 1 Demographic characteristics of patients of the two groups

\begin{tabular}{llll}
\hline $\begin{array}{l}\text { Demographic } \\
\text { characteristics }\end{array}$ & $\begin{array}{l}\text { AGA } \\
(n=30)\end{array}$ & $\begin{array}{l}\text { SGA } \\
(n=52)\end{array}$ & $\begin{array}{l}P \\
(t \text { test })\end{array}$ \\
\hline Gender $(\mathrm{M} / \mathrm{F})$ & $16 / 14$ & $32 / 20$ & 0.621 \\
Age $($ years $)$ & $12.27(1.74)$ & $12.40(2.47)$ & 0.800 \\
Weight $(\mathrm{kg})$ & $46.42(9.61)$ & $48.67(14.42)$ & 0.449 \\
Height $(\mathrm{cm})$ & $153.21(10.26)$ & $153.93(16.14)$ & 0.827 \\
Body size & $1.41(0.17)$ & $1.40(0.29)$ & 0.864 \\
BMI $\left(\mathrm{kg} / \mathrm{m}^{2}\right)$ & $19.69(3.03)$ & $20.86(4.39)$ & 0.200 \\
\hline
\end{tabular}

AGA, appropriate weight for gestational age (normal birth weight); SGA, small for gestational age (low birth weight); M, male; F, female; BMI, body mass index 
contour; we measured the arterial waveform in the nondominant arm with a cardiovascular profiling instrument (HDI/ Pulse Wave CR-2000; Hypertension Diagnostics). Briefly, the tonometer was applied to the patient's radial artery at the wrist overlying the radial bony prominence. The subject's arm was supported by a wrist stabilizer for optimal positioning and minimal movement during the measurements. The cuff for BP measurement was placed on the contralateral arm and inflated concurrently with the pulse waveform recording for calibration; a 30-s interval of analogue waveforms was digitized at 200 samples/s, and a beat marking algorithm was determined the beginning of systole, peak systole, onset of diastole, and end of diastole for all beats in the 30-s measurement period. The elasticity indices of the arteries $(\mathrm{C} 1$ and $\mathrm{C} 2)$ were quantified during the diastolic portion of the heart cycle (mean recording time $30 \mathrm{~s}$ ). According to the modified Windkessel model of circulation, $\mathrm{C} 1$ is a marker of large artery elasticity and $\mathrm{C} 2$ is a marker of small artery elasticity. Heart rate, mean arterial pressure (MAP), and stroke volume were also calculated from the radial pressure waveform using HDI/Pulse Wave CR-2000 software. These hemodynamic parameters (i.e. MAP and stroke volume) are used in multivariate algorithms for determining $\mathrm{C} 1$ and $\mathrm{C} 2$. The full method has already been validated and described in detail in adult patients [18]; however, they have not yet been validated in the pediatric population [28].

\section{Statistical analysis}

All variables were tested for normal distribution by the Kolmogorov-Smirnov test and for variance homogeneity by the Levene test. The variables are expressed as average values and SD or as absolute frequency.

The AGA and SGA groups were compared under basal conditions using the unpaired $t$ test or proportions test. The one-way analysis of variance, with the Dunn post hoc test for multiple comparisons when necessary, was used to compare the determinations of each group (AGA and SGA). A $P$ value of $<0.05$ was considered to be statistically significant. The statistical analysis was performed using SPSS statistical software ver. 14.0 (SPSS, Chicago, IL).

\section{Results}

Subjects and vascular function

A total of 82 children/adolescents were studied: 30 AGA (16 males, 14 females) and 52 SGA ( 32 males, 20 females). Table 1 summarizes the demographic characteristics of all subjects at the time of the study. There were no significant differences between the two groups in terms of demographic variables, with the children/adolescents in the AGA and
SGA groups being homogeneous for gender distribution, age, weight, height, body size, and body mass index (BMI).

With respect to vascular function and arterial elasticity, the comparison between the two groups at basal time revealed significant differences between the AGA and SGA groups in SBP $(t$ test, $P<0.01$, with a difference of + $7.6 \mathrm{~mm} \mathrm{Hg}$ ) and DBP ( $t$ test, $P<0.05$, with a difference of + $4.23 \mathrm{~mm} \mathrm{Hg}$ ); significant negative differences were highlighted in $\mathrm{C} 1$ ( $t$ test, $P<0.01$, with a difference of $-2.21 \mathrm{ml} /$ $\mathrm{mmHg} \times 10)$ and in $\mathrm{C} 2(t$ test, $P<0.01$ with a difference of $-1.53 \mathrm{ml} / \mathrm{mmHg} \times 100)$. There were also significant difference in vascular resistances (VR) $(t$ test, $P<0.05$ with +151 dyne $\left./ \mathrm{s} \times \mathrm{cm}^{-5}\right)$. However, there was no statistical difference between the two groups for the pulse pressure (PP) variable ( $t$ test, $P=0.177$ ). (Table 2$)$

Post-ischemia vascular function

The changes induced by the ischemic stress were analyzed separately in each group, AGA and SGA, at standardized times, followed by an analysis of the changes between the two groups.

After the standardized ischemic stress had been applied to the brachial artery, we noticed a modest but not significant decrease of SBP $(P=0.349)$, DBP $(P=0.149)$, and pulse pressure (PP) $(P=0.191)$ in the AGA group. The multiple comparisons in the AGA group showed a significant difference for the variables $C 1 \quad(P=0.949), C 2 \quad(P=0.348)$, and vascular resistance $(P=0.949)$. In the SGA group, the change in SBP $(P=0.096)$, DBP $(P=0.444)$, PP $(P=0.075)$, and $\mathrm{C} 2(P=0.105)$ following application of the ischemic stimulus was not significant; however, there was a significant increase of $\mathrm{C} 1(P<0.01)$ and a significant reduction of vascular resistance (VR) $(P<0.001)$. In particular, we found a significant increase $(+1.73 \mathrm{mmHg})$ between basal time and the last time for $\mathrm{C} 1$ (Dunn post hoc, $P<0.05$ ), and a significant reduction between basal time and each time of post-ischemic determination for VR $\left(-117 \mathrm{dyne} / \mathrm{s} \times \mathrm{cm}^{-5}\right)$ (Table 3).

Our analysis of post-ischemic vascular compliance in both groups revealed a vasodilatory response, which did not reach statistical significance in the AGA. In contrast, a more lively vasodilator response was observed in the SGA group, which was characterized by a greater decrease in SBPc $(-4.1 \mathrm{~mm} \mathrm{Hg}$ in the SGA group vs. $-2.1 \mathrm{~mm} \mathrm{Hg}$ in the AGA group), DBP ( -1.57 vs. $-1.3 \mathrm{~mm} \mathrm{Hg}$, respectively) and VR ( -117 in SGA vs. -116 in AGA). We also observed a greater increase in the indexes of macrovascular compliance $[+1.73$ vs. $+0.4(\mathrm{ml} / \mathrm{mm} \mathrm{Hg} \times 10)$ in SGA vs. AGA groups $]$ and microvascular elasticity $[+0.82$ vs. +0.35 (in $\mathrm{ml} / \mathrm{mm} \mathrm{Hg} \times 100$ ) in SGA vs. AGA groups]. The percentage changes from pre- to post-ischemia in the SGA group are shown in Fig. 1. 
Table 2 Vascular compliance in the appropriate for gestational age (AGA) group

\begin{tabular}{llllll}
\hline Vascular variables $^{\mathrm{a}}$ & Basal & P-I & P-I $_{2}$ & P-I $_{3}$ & P-I $_{4}$ \\
\hline SBP & $111.1(10.3)^{* *}$ & $109.4(9.3)$ & $111.2(9.92)$ & $109(7.66)$ & $111.6(9.84)$ \\
DBP & $54.8(6.1)$ & $54.4(6.03)$ & $54.4(7.66)$ & $51.4(9.81)$ & $53.5(6.75)$ \\
PP & $56.1(6.3)^{* *}$ & $53.6(5.42)$ & $53.73(6.95)$ & $56.33(9.05)$ & $54.6(5.51)$ \\
$C_{1}$ & $12.89(4.07)^{*}$ & $12.83(4.02)$ & $13.24(5.78)$ & $12.82(4.24)$ & $12.66(3.31)$ \\
$C_{2}$ & $7.78(2.7)^{* *}$ & $8.13(2.98)$ & $7.65(1.42)$ & $7.50(1.79)$ & $7.22(2.07)$ \\
VR & $1184(230)$ & $1068(346)$ & $1157(186)$ & $1105(174)$ & $1166(213)$ \\
\hline
\end{tabular}

* $P=0.04 ; * * P=0.002$, basal values versus SGA

Values are given as the mean with the standard deviation (SD) in parenthesis

Basal, Mean of three consecutive determinations, each of 5-min duration; $\mathrm{P}_{\mathrm{I}} \mathrm{I}_{1,2,3,4}$, post-ischemic determination, each of 5-min duration

${ }^{a}$ SBP, Systolic blood pressure (mmHg); DBP, diastolic blood pressure (mmHg); PP, pulse pressure ( $\mathrm{mmHg}$ ); $\mathrm{C}_{1}$, macrovascular compliance (m1/ $\mathrm{mm} \mathrm{Hg} \times 10) ; \mathrm{C}_{2}$, microvascular compliance $(\mathrm{ml} / \mathrm{mm} \mathrm{Hg} \times 100)$; VR, vascular resistance (dyne $\left./ \mathrm{s}^{\circ} \mathrm{cm}^{-5}\right)$, before and after brachial ischemia (3')

\section{Discussion}

Knowledge of the characteristics of the vascular tree in IUGR infants, children, and young adults can help clarify the underlying mechanisms that are at the origin of hypertension in this population at increased risk of CVD in adulthood.

In the SGA group we observed an increase in systolic, pulse, and diastolic blood pressure and in vascular resistances; the elasticity of the large and small vessels was lower in the SGA than in the AGA group. These data are in line with those reported by other authors [1, 26-29] who found an increase in SBP in many epidemiological studies, suggesting an inverse relationship between birth weight and hypertension. The increase in these hemodynamic parameters, associated with significantly worse vascular compliance in the SGA group, could indicate that in this group of selected healthy children/adolescents there are very early signs of functional impairment of the arterial wall, which in turn depends on the function of endothelial cells. The endothelium controls permeability, regulates vascular growth, and keeps the blood vessels open and free from clots by releasing a number of vasoactive factors, such as nitric oxide (NO), angiotensin II, endothelin, among others. Endothelial impairment, when identified, is an early risk factor of coronary or peripheral artery disease. Arterial stiffness also seems to have a genetic component that is largely independent of the influence of blood pressure and other cardiovascular risk factors [30-35]

When we provoked a standardized ischemic stress at the brachial artery of subjects in the AGA group, we observed a decrease in the SBP $(-2.1 \mathrm{~mm} \mathrm{Hg})$, DBP $(-3.4 \mathrm{~mm} \mathrm{Hg}), \mathrm{PP}$ $(-2.5 \mathrm{~mm} \mathrm{Hg})$, and $\operatorname{VR}\left(-111 \mathrm{dyne} / \mathrm{s} \times \mathrm{cm}^{-5}\right)$ and an increase in the $\mathrm{C} 1(+0.35 \mathrm{ml} / \mathrm{mm} \mathrm{Hg} \times 10)$ and $\mathrm{C} 2$ $(+0.35 \mathrm{ml} / \mathrm{mm} \mathrm{Hg} \times 100)$. Following the same stress in the SGA group, we observed a more lively vasodilator response that was characterized by a greater decrease in SBP (-4.1 mm Hg), DBP (-1.53 mm Hg), PP (-2.86 mm Hg), and VR $\left(-117\right.$ dyne/s $\left.\times \mathrm{cm}^{-5}\right)$. We also observed a greater increase in the indexes of macrovascular compliance $(\mathrm{C} 1+$ $1.73 \mathrm{ml} / \mathrm{mm} \mathrm{Hg} \times 10)$ and microvascular elasticity $(\mathrm{C} 2+$ $0.82 \mathrm{ml} / \mathrm{mm} \mathrm{Hg} \times 100$ ). These data support the hypothesis that in the SGA group the response induced by ischemic

Table 3 Vascular compliance in the SGA group

\begin{tabular}{llllll}
\hline Vascular variables $^{\mathrm{a}}$ & Basal & P-I & P-I & P-I & P-I \\
\hline SBP & $118.7(11.2)^{* *}$ & $115.8(12.2)$ & $116.6(12.1)$ & $116.3(10.6)$ & $114.6(11.05) \S$ \\
DBP & $59.03(7.6)$ & $59.6(9.86)$ & $58.1(9.11)$ & $57.5(7.27)$ & $59.1(6.73)$ \\
PP & $58.4(7.9)^{* *}$ & $56.1(10.1)$ & $57.5(9.17)$ & $57.3(9.5)$ & $55.54(7.84) \S \S$ \\
$C_{1}$ & $10.68(3.37)^{*}$ & $12.21(4.57)$ & $10.96(5.23)$ & $11.94(4.22)$ & $12.41(4.57) \S \S$ \\
$C_{2}$ & $6.25(2.0)^{* *}$ & $6.52(2.46)$ & $6.27(2.43)$ & $6.37(2.68)$ & $7.07(2.82) \S \S$ \\
VR & $1335(350)$ & $1256(263)$ & $1242(254)$ & $1218(196)$ & $1228(224) \S \S$ \\
\hline
\end{tabular}

$* P<0.04 ; * * P<0.002$, basal values vs. AGA

$\S P<\mathrm{a} 0.02 ; \S \S P<0.002$, basal values vs. post-ischemic modifications

Values are given as the mean with the SD in parenthesis

SGA, small for gestational age; AGA, appropriate for gestational age; SBP, systolic blood pressure; DBP, diastolic blood pressure; PP, pulse pressure; $\mathrm{C}_{1}$, macrovascular compliance $(\mathrm{ml} / \mathrm{mm} \mathrm{Hg} \times 10) ; \mathrm{C}_{2}$, microvascular compliance $(\mathrm{ml} / \mathrm{mm} \mathrm{Hg} \times 100)$; VR, vascular resistance 
\% Changes From Pre- to Post-Ischemia in the SGA group

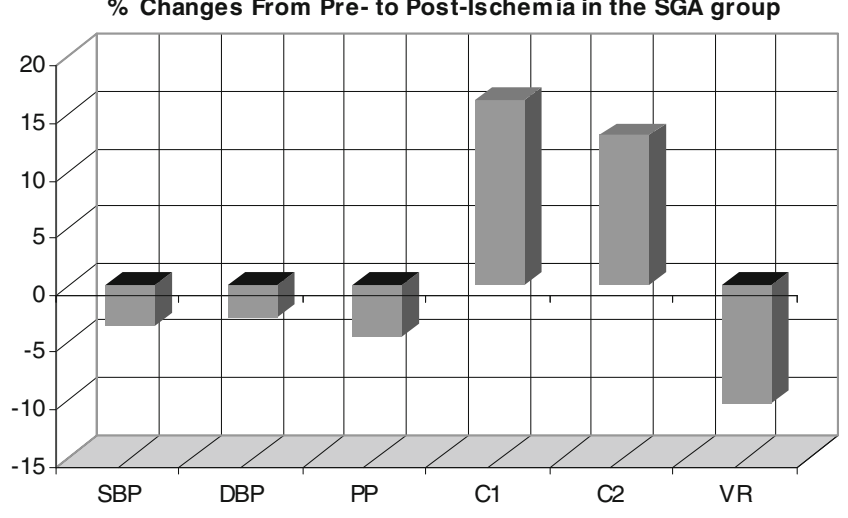

Fig. 1 Changes $(\%)$ in systolic $(S B P)(P<0.02)$ and diastolic blood pressure $(D B P)(P=$ not significant $)$, pulse pressure $(P P)(P<0.02)$, macrovascular compliance $(C 1)(P<0.002)$, microvascular compliance (C2) $(P<0.002)$, vascular resistance $(V R)(P<0.002)$ in children/adolescents born small for gestational age $(S G A)$ from pre- to postischemia

stress is greater, which could indicate that endothelial cells are chronically overstimulated to supply organs and tissues. This pathophysiological condition could not only increase oxidative stress on the vascular tree, thereby favoring progressive early damage to the vascular wall, for example by increasing stiffness in large and small arteries, but it could also explain the early appearance of hypertensive disease with the manifestation of endothelial dysfunction due to decreased synthesis and release of NO and other vasorelaxant substances. Mechanical forces, comprising both unidirectional laminar and oscillatory shear, are increasingly being recognized as important inducers of vascular NO and generators of reactive oxidative species (ROS). On the other hand, oscillatory shear is linked to increased ROS production with consequent oxidative damage, as occurs in hypertension. As recently reviewed, shear stress alone potently stimulates the release of vasorelaxant mediators, such as NO, enhances endothelial survival, and counters cell adhesion and thrombosis [36].

Our study has a number of limitations. First, the two experimental groups consisted of a relatively small number of children and adolescents matched for age, but the match for gender and height was not perfect. Secondly, experience with applanation tonometry and other technologies (Doppler ultrasound, photoplethysmography, among others) in pediatric patients is limited; methods such as Doppler ultrasound are strictly dependent on highly trained personnel, and the few studies performed to date have involved relatively few subjects [28, 37]. However, such equipment has a relatively low cost, is easy to use, and is acceptable to patients; in addition, such equipment provides important information on the vascular wall and flow-mediated dilation.

In conclusion, we found a raised SBP and a reduced vascular elasticity under basal conditions in SGA children/ adolescents; after the application of ischemic stress, the large and small vessels of these children/adolescents manifested a stronger vasodilation than those of AGA subjects. However, further studies with more subjects are required so that the prognostic value, relative to established predictors of risk, may be fully defined, especially in the pediatric population. Moreover we want to stress that the applanation tonometry method is absolutely not invasive and would appear to be particularly suitable for the pediatric/adolescent patient population, for which we need to have simple techniques that are non-invasive so as to increase the compliance of families and healthy children/adolescents to prevent cardiovascular disease [38].

Acknowledgments The authors would like to acknowledge the help of Monte dei Paschi di Siena Foundation, the fruitful collaboration of Anna Lusini, secretary of Department of Pediatrics, Obstetrics and Reproductive Medicine. We would like to thank our children and adolescents and their parents for the important contribution to the achievement of the study.

\section{Competing interest None.}

Funding sources This study was funded by MIUR (Ministry of Education, University and Research) PRIN 2003, by the University Research Plan (PAR), and by the Monte dei Paschi di Siena Foundation.

Open Access This article is distributed under the terms of the Creative Commons Attribution License which permits any use, distribution, and reproduction in any medium, provided the original author(s) and the source are credited.

\section{References}

1. Barker DJ, Osmond C, Golding J, Kuh D, Wadsworth ME (1989) Growth in utero, blood pressure in childhood and adult life, and mortality from cardiovascular disease. Br Med J 298:564-567

2. Barker DJ, Osmond C (1986) Infant mortality, childhood nutrition, and ischaemic heart disease in England and Wales. Lancet 1:10771081

3. Davies AA, Smith GD, May MT, Ben-Shlomo Y (2006) Association between birth weight and blood pressure is robust, amplifies with age, and may be underestimated. Hypertension 48:431-436

4. Prentice AM, Moore SE (2005) Early programming of adult diseases in resource poor countries. Arch Dis Child 90:429-432

5. Siewert-Delle A, Ljungman S (1998) The impact of birth weight and gestational age on blood pressure in adult life: a populationbased study of 49-year-old men. Am J Hypertens 11:946-953

6. Kistner A, Celsi G, Vanpee M, Jacobson SH (2000) Increased blood pressure but normal renal function in adult women born preterm. Pediatr Nephrol 15:215-220

7. Law CM, Shiell AW (1996) Is blood pressure inversely related to birth weight? The strength of evidence from a systematic review of the literature. J Hypertens 14:935-941

8. Huxley RR, Shiell AW, Law CM (2000) The role of size at birth and postnatal catch-up growth in determining systolic blood pressure: a systematic review of the literature. J Hypertens 18:815-831 
9. Irving RJ, Belton NR, Elton RA, Walker BR (2000) Adult cardiovascular risk factors in premature babies. Lancet 355:2135-2136

10. Hofman PL, Regan F, Jackson WE, Jefferies C, Knigh DB, Robinson EM, Cutfield WS (2004) Premature birth and later insulin resistance. N Engl J Med 351:2179-2186

11. Norman M (2008) Low birth weight and the developing vascular tree: a systematic review. Acta Paediatr 97:1165-1172

12. Cheung YF, Wong KY, Lam BC, Tsoi NS (2004) Relation of arterial stiffness with gestational age and birth weight. Arch Dis Child 89:217-221

13. Frayling TM, Hattersley AT (2001) The role of genetic susceptibility in the association of low birth weight with type 2 diabetes. $\mathrm{Br}$ Med Bull 60:89-101

14. Gluckman PD, Hanson MA, Mitchell MD (2010) Developmental origins of health and disease reducing the burden of chronic disease in the next generation. Genome Med 2(2):14

15. Tremblay J, Hamet P (2008) Impact of genetic and epigenetic factors from early life to later disease. Metabolism 57[Suppl 2]: $\mathrm{S} 27-\mathrm{S} 31$

16. Cohn JN, Quyyumi AA, Hollenberg NK, Jamerson KA (2004) Surrogate markers for cardiovascular disease: functional markers. Circulation 109[25 Suppl 1]:31-34

17. Feletou M, Vanhoutte PM (2006) Endothelial dysfunction: a multifaceted disorder. Am J Physiol Heart Circ Physiol 291:H985H1002

18. O'Rourke MF, Staessen JA, Vlachopoulos C, Duprez D, Plante GE (2002) Clinical applications of arterial stiffness; definitions and reference values. Am J Hypertens 15:426-444

19. Leibovitz E, Beniashvili M, Zimlichman R, Freiman A, Shargorodsky M, Gavish D (2003) Treatment with amlodipine and atorvastatin have additive effect in improvement of arterial compliance in hypertensive hyperlipidemic patients. Am J Hypertens 16:715-718

20. Duprez DA, De Buyzere ML, De Bruyne L, Clement DL, Cohn JN (2001) Small and large artery elasticity indices in peripheral arterial occlusive disease (PAOD). Vasc Med 6:211-214

21. Leeson CP, Whincup PH, Cook DG, Donald AE, Papacosta O, Lucas A, Deanfield JE (1997) Flow-mediated dilation in 9- to 11-year-old children: the influence of intrauterine and childhood factors. Circulation 96:2233-2238

22. Leeson CPM, Kattenhorn M, Morley R, Lucas A, Deanfield JE (2001) Impact of low birth weight and cardiovascular risk factors on endothelial function in early adult life. Circulation 103:1264-1268

23. Goodfellow J, Bellamy MF, Gorman ST, Brownlee M, Ramsey MW, Lewis MJ, Davies DP, Henderson AH (1998) Endothelial function is impaired in fit young adults of low birth weight. Cardiovasc Res 40:600-606

24. Martin H, Hu J, Gennser G, Norman M (2000) Impaired endothelial function and increased carotid stiffness in 9-year-old children with low birthweight. Circulation 102:2739-2744
25. Aggoun Y, Szezepanski I, Bonnet D (2005) Noninvasive assessment of arterial stiffness and risk of atherosclerotic events in children. Pediatr Res 58:173-178

26. Alkalay AL, Graham JM Jr, Pomerance JJ (1998) Evaluation of neonates born with intrauterine growth retardation: review and practice guidelines. J Perinatol 18:142-151

27. Lee PA, Chernausek SD, Hokken-Koelega ACS, Czernichow P (2003) International Small for Gestational Age Advisory Board Consensus Development Conference Statement: management of short children born small for gestational age, April 24-October 1, 2001. Pediatrics 111:1253-1261

28. Urbina EM, Williams RV, Alpert BS, Collins RT, Daniels SR, Hayman L, Jacobson M, Mahoney L, Mietus-Snyder M, Rocchini A, Steinberger J, McCrindle B (2009) Non invasive assessment of subclinical atherosclerosis in children and adolescents: recommendations for standard assessment for clinical research: a scientific statement from the American Heart Association. Hypertension 54:919-950

29. Tounian P, Aggoun Y, Dubern B, Varille V, Guy-Grand B, Sidi D, Girardet JP, Bonnet D (2001) Presence of increased stiffness of the common carotid artery and endothelial dysfunction in severely obese children: a prospective study. Lancet 358:1400-1404

30. Deanfield JE, Halcox JP, Rabelink TJ (2007) Endothelial function and dysfunction: testing and clinical relevance. Circulation 115:1285-1295

31. Faury G, Pezet M, Knutsen RH, Boyle WA, Heximer SP, McLean SE, Minkes RK, Blumer KJ, Kovacs A, Kelly DP, Li DY, Starcher B, Mecham RP (2003) Developmental adaptation of the mouse cardiovascular system to elastin haploinsufficiency. J Clin Invest 112:1419-1428

32. Kingwell B, Boutouyrie P (2007) Genetic influences on the arterial wall. Clin Exp Pharmacol Physiol 34:652-657

33. Nair N, Oka RK, Waring LD, Umoh EM, Taylor CB, Cooke JP (2005) Vascular compliance versus flow-mediated vasodilation: correlation with cardiovascular risk factors. Vasc Med 10:275-283

34. Armitage JA, Khan IY, Taylor PD, Nathanielsz PW, Poston L (2004) Developmental programming of the metabolic syndrome by maternal nutritional imbalance: how strong is the evidence from experimental models in mammals? J Physiol 561(Pt 2):355-377

35. Lurbe E, Torro MI, Carvajal E, Alvarez V, Redon J (2003) Birth weight impacts on wave reflections in children and adolescents. Hypertension 41:646-650

36. Paravicini TM, Touyz RM (2006) Redox signaling in hypertension. Cardiovasc Res 71:247-258

37. Collins RT, Somes GW, Alpert BS (2008) Differences in arterial compliance among normotensive adolescent groups. Pediatr Cardiol 29:929-934

38. Oliver JJ, Webb DJ (2003) Noninvasive Assessment of Arterial Stiffness and Risk of Atherosclerotic Events. Arterioscler Thromb Vasc Biol 23:554-566 